Hal. 336 - 349

\title{
PENGUKURAN KINERJA DINAS KELAUTAN DAN PERIKANAN KABUPATEN SITUBONDO
}

\author{
Tomy Rudyanto \\ Dinas Kelautan dan Perikanan Kabupaten Situbondo \\ tomyrudyanto@yahoo.com \\ Imam Suroso \\ Fakultas Ekonomi dan bisnis \\ imamsuroso.unej@gmail.com
}

Agung Budi S.

Fakultas Ekonomi dan Bisnis Universitas Jember

\begin{abstract}
Performance measurement is critical for public sector organizations to determine the sucess level in implementing strategies to achieve its vision and mission. Therefore, an analytical tool is needed to measure government performance and to provide comprehensive information from both financial and non-financial aspects. The use of balanced scorecard as the measurement method could broaden the perspective, not only from the financial perspective, but also from the customer, internal business processes, and learning and growth perspectives. The objective of this study was to analyze the performance of the Department of Marine and Fisheries of Situbondo Regency in 2015 using a balanced scorecard approach. This was a descriptive qualitative research applying a case study. The informants were the local people and staffs of the Department of Marine and Fisheries of Situbondo Regency. Value for money analysis was used in measuring financial perspective and service quality (servqual), while Important Performance Analysis (IPA) used in measuring other perspectives. Conclusion was drawn based on the scoring results. Results showed that, in overall, the performance of the Department of Marine and Fisheries of Situbondo Regency was in "good" category. Results of servqual analysis showed that all aspects had negative values, meaning that the expectations were higher than perceptions so the performance should be improved based on the priorities indicated in the IPA analysis.
\end{abstract}

Keywords: Performance Measurement, Balanced Scorecard.

Abstrak:Pengukuran kinerja dibutuhkan oleh organisasi sektor publik untuk mengetahui tingkat keberhasilan penerapan strategi dalam upaya pencapaian visi dan misi.Oleh karena itu, dibutuhkan sebuah alat analisis yang dapat mengukur kinerja pemerintah dan dapat memberikan informasi yang komprehensif baik dari aspek keuangan maupun non keuangan. Penggunaan balanced scorecard sebagai metode pegukuran berperan memperluas perspektif tidak hanya mengukur dari perspektif keuangan saja tetapi juga dari perspektif pelanggan, perspektif proses bisnis internal, serta perspektif pertumbuhan dan pembelajaran. Tujuan dari penelitian ini adalah untuk menganalisis kinerja Dinas Kelautan dan Perikanan Kabupaten Situbondo pada tahun 2015 dengan pendekatan balanced scorecard. Penelitian ini menggunakan analisis deskriptif kualitatif dengan studi kasus. Informan berasal dari masyarakat dan staf Dinas Kelautan dan Perikanan. Analisisvalue for money digunakan dalammengukur perspektif keuangan dan service quality(servqual) 
sedangkan/mportant Performance Analysis(IPA) digunakan dalam mengukur perspektif lainnya. Kemudian dilakukan scoring secara keseluruhan untuk mendapatkan kesimpulan. Hasil penelitian menunjukkan bahwa secara keseluruhan, kinerja Dinas Kelautan dan Perikanan Kabupaten Situbondo masuk dalam kategori "baik". Analisisservqual menunjukkan semua aspek bernilai negatif yang artinya harapan yang dimiliki lebih tinggi dari persepsinya, sehingga perlu ditingkatkan kinerjanya berdasarkan skala prioritas yang ditunjukkan pada analisis IPA.

Kata Kunci: Pengukuran Kinerja, Balanced Scorecard.

\section{PENDAHULUAN}

Pelayanan publik merupakan bagian dari pelaksanaan birokrasi pemerintah, tujuan penyelenggaraan birokrasi adalah menghasilkan sesuatu yang bernilai secara cepat, tepat, dan dengan biaya yang sangat murah. Untuk mengetahui kinerja sebuah organisasi publik diperlukan sebuah pengukuran kinerja sehingga dapat diketahui apakah organisasi tersebut telah berhasil mencapai visi dan misinya melalui pelaksanaan strategi yang telah dirumuskannya. Pengukuran kinerja bertujuan untuk memberikan arahan dalam penyusunan rencana kerja serta sebagai bahan evaluasi kerja yang telah dilakukan dalam mencapai sasaran organisasi (Mutaqien, 2006: 20).

Pengukuran kinerja pada awalnya hanya difokuskan pada pengukuran aspek keuangan saja. Pengukuran aspek finansial saja tidak mampu memberikan gambaran yang obyektif dan komprehensif terhadap kinerja organisasi secara keseluruhan karena tidak mampu menguraikan strategi-strategi yang telah dilakukan oleh organisasi dalam mencapai target dan tujuan organisasi. Peran Balanced Scorecard dalam pengukuran kinerja organisasi adalah memperluas perspektif atau pendekatan pada setiap unit organisasi yang saling berkaitan dalam melaksanakan strategi organisasi, dan tidak hanya melalui perspektif keuangan saja namun juga melalui perspektif pelanggan, perspektif bisnis internal dan perspektif pembelajaran dan pertumbuhan (Kaplan dan Norton, 2000: 18)

Pengukuran kinerja yang selama ini dilakukan di Dinas Kelautan dan Perikanan Kabupaten Situbondo masih belum menggunakan balanced scorecard dan masih berfokus pada pengukuran kinerja dari aspek keuangan saja. Motivasi penggunaan BSC pada Dinas Kelautan dan Perikanan adalah untuk memberikan gambaran yang lebih lengkap tentang pengukuran kinerja di instansi tersebut dari aspek non keuangan. Sektor kelautan dan perikanan merupakan salah satu sektor unggulan di Kabupaten Situbondo sehingga pengukuran kinerja pada instansi pemerintah tersebut diharapkan dapat memberikan masukan bagi peningkatan pertumbuhan ekonomi di Kabupaten Situbondo, khususnya pembangunan sektor perikanan dan kelautan.

Machmud (2013) menyatakan bahwa konsep balanced scorecard memadukan kinerja anggaran keuangan dengan kinerja non keuangan sehingga sangat relevan untuk 
diterapkan pada pengukuran kinerja pemerintahan dalam pengelolaan keuangan daerah yang baik. APBD harus disusun dengan kinerja untuk mencapai output, outcome, benefit dan impact yang selaras dengan misi dan visi yang telah ditetapkan.

Berdasarkan uraian pada latar belakang tersebut, maka diperlukan sebuah pengukuran kinerja untuk memberikan gambaran menyeluruh dengan mengakomodasi pengukuran kinerja dari berbagai aspek baik aspek keuangan maupun aspek non keuangan. Pemakaian konsep balanced scorecard diharapkan mampu memberikan gambaran yang lebih komprehensif terhadap pengukuran kinerja pada Dinas Kelautan dan Perikanan Kabupaten Situbondo. Tujuan penelitian penelitian ini adalah untuk "Menganalisis kinerja Dinas Kelautan dan Perikanan Kabupaten Situbondo pada tahun 2015 dengan pendekatan aspek keuangan dan non keuangan melalui pendekatan balanced scorecard."

\section{Metodologi}

Penelitian ini tergolong dalam penelitian kualitatif dengan studi kasus, proses pengambilan kesimpulan dilakukan dengan metode deduktif dan induktif. Data yang digunakan dalam penelitian ini adalah data primer dan data sekunder. Responden terdiri dari karyawan PNS di DKP serta stakeholder. Sedangkan informan terdiri dari Kepala Dinas, Kasubbag Perencanaan, Kepala UPTD, staff DKP dan stakeholder yang menggunakan jasa pelayanan instansi baik secara langsung ataupun tidak langsung. Data primer dalam penelitian diperoleh dengan teknik wawancara, teknik kuesioner dan dokumentasi.Sedangkan data sekunder merupakan data yang diperoleh dari sumber data secara tidak langsung, yang dapat berupa dokumen, laporan, arsip, media cetak, media elektronik dan studi pustaka yang berkaitan dengan tema dan fokus penelitian.

Penentuan sampel dalam penelitian ini menggunakan teknik purposive sampling dimana penentuan sampel ditentukan secara sengaja oleh peneliti dengan memperhatikan pertimbangan tertentu (Sugiyono, 2010:122).

Teknik analisis data secara deskriptif dilakukan dengan menyajikan data yang diperoleh dari hasil kuesioner dalam bentuk tabel, diagram atau grafik. Data-data yang akan ditampilkan dalam bentuk analisis deskriptif meliputi data yang diperoleh dari metode BSC yang terdiri dari empat pendekatan, yaitu:

a. Perspektif Keuangan, yaitu analisis terhadap kinerja keuangan diukur menggunakan value for money dengan menganalisis rasio ekonomis, efisiensi dan efektifitas anggaran. Analisis perspektif keuangan dilakukan sebagai berikut:

Ekonomis $=\frac{\text { Realisasi Belanja }}{\text { Anggaran Belanja }} \times 100 \%$




Efisiensi $=\frac{\text { Realisasi Belanja }}{\text { Realisasi Pendapatan }} \times 100 \%$
Efektivitas $=\frac{\text { Realisasi Penerimaan PAD }}{\text { Target Penerimaan PAD }} \times 100 \%$

b. Perspektif Pelanggan, pada perspektif ini akan dilakukan pengukuran menggunakan lima dimensi seperti Tangibility yang meliputi tampilan fisik bangunan, sarana dan prasarana, penampilan pegawai, serta ketersediaan fasilitas pendukung; Reliability, yaitu kesediaan para pegawai dalam memberikan pelayanan secara tepat dan akurat; Responsiveness, yaitu kerelaan pegawai dalam memberikan pertolongan dan tanggapan terhadap keluhan publik; Assurance, yaitu kemampuan para petugas dalam memberikan keyakinan terhadap stakeholder dan Emphaty, yaitu mencakup perlakuan dan perhatian petugas dalam memberikan pelayanan kepada stakeholder.

c. Perspektif proses bisnis internal memfokuskan pada indikator kualitas jasa dengan menggunakan tiga dimensi yaitu dimensi fasilitas yang mencakup peralatan kerja seperti komputer, printer, fasilitas internet, kendaraan operasional dan sarana penunjang lainnya yang tersedia dalam jumlah yang cukup dan dalam kondisi baik dan layak pakai; sumberdaya manusia yang dimiliki oleh instansi telah tepat jumlah dan tepat spesialisasi, artinya pegawai yang dimiliki jumlahnya sesuai dengan kebutuhan serta memiliki kualifikasi dan latar pendidikan yang mendukung pelaksanaan teknis pembangunan kelautan dan perikanan; dan proses yang dimiliki dan diterapkan oleh instansi dalam menjalankan tugas dan fungsinya. Hal ini mencakup kesesuaian jadwal pelaksanaan program kegiatan sesuai dengan yang terdapat di rencana kerja, pegawai mampu mengatasi hambatan dalam pekerjaannya, pegawai mampu memberikan pelayanan sesuai dengan ketentuan standart pelayanan minimum (SPM).

d. Perspektif pertumbuhan dan pembelajaran meliputi dua dimensi yaitu dimensi kemampuan yang meliputi kepuasan pegawai terkait kebijakan instansi dalam meningkatkan pengetahuan dan kemampuan pegawai dalam meningkatkan kinerja organisasi dan dimensi kemampuan yang meliputi kepuasan pegawai terkait kebijakan instansi dalam meningkatkan pengetahuan dan kemampuan pegawai dalam meningkatkan kinerja organisasi

Skala pengukuran pada aspek non keuangan digunakan skala likert dimana untuk pengukuran secara kualitatif maka digunakan pemberian skor sebagai berikut: 5 = sangat puas/setuju, 4 = puas/setuju, 3=cukup puas/setuju, 2=tidak puas/setuju, 1=sangat tidak puas/setuju (Riduwan, 2009:12). Kualitas pelayanan akan ditampilkan dalam bentuk grafik 
dengan menggunakan Importance-Performance Analysis (IPA) (Martilla dan James, 1977). Untuk melihat apakah kualitas kinerja yang diberikan sesuai dengan kualitas kinerja yang diharapkan maka dipergunakan analisis skor servqual. Nilai skor rata-rata dibandingkan antara nilai rata-rata skor persepsi dan nilai rata-rata skor harapan, sehingga diperoleh nilai servqual atau gap yang dapat bernilai negatif dan positif.

Skor servqual digunakan untuk mengetahui kualitas pelayanan yang diterima oleh pelanggan (Tjiptono, 2005:137), yang dihitung dengan rumus:

\begin{tabular}{|c|}
\hline Skor ServQual $=$ Total Skor Persepsi - Total Skor Harapan \\
Hasil perhitungan skor ServQual diinterprestasikan dengan kategori sebagai
\end{tabular}
berikut:

a. Jika menghasilkan angka positif, berarti kualitas pelayanan yang dirasakan melebihi tingkat pelayanan yang diharapkan atau sangat baik ( Excellent).

b. Jika menghasilkan angka negatif, berarti kualitas pelayanan yang dirasakan masih dirasa kurang bila dibandingkan dengan yang diharapkan atau tidak memuaskan (Poor).

c. Jika menghasilkan angka nol, berarti kualitas pelayanan yang dirasakan sesuai dengan tingkat pelayanan yang diharapkan atau sangat baik (Good).

Dalam metode pengambilan keputusan terhadap hasil yang diperoleh pada pengolahan data deskriptif menggunakan skala dan instrument berikut :

1. Perspektif Keuangan

Parameter yang di gunakan berdasarkan Keputusan Menteri Dalam Negeri Nomor 690.900-327 tahun 1996

a. Ekonomis

Tabel 1

\begin{tabular}{lll}
\hline & Nilai $(\%)$ & Kategori \\
\hline$>100 \%$ & Tidak efisien \\
\hline $90 \%-100 \%$ & Kurang efisien \\
\hline $80 \%-90 \%$ & Cukup efisien \\
\hline $60 \%-80 \%$ & Efisien \\
\hline$<60 \%$ & Sangat efisien \\
\hline
\end{tabular}

b. Efisiensi

Tabel 2

\begin{tabular}{|c|c|c|}
\hline Nilai (\%) & Skala & Kategori \\
\hline$<60 \%$ & 5 & Sangat efisien \\
\hline
\end{tabular}




\begin{tabular}{lll}
\hline & Nilai (\%) & \multicolumn{2}{c}{ Skala } & Kategori \\
\hline $60 \%-80 \%$ & 4 & Efisien \\
\hline $80 \%-90 \%$ & 3 & Cukup efisien \\
\hline $90 \%-100 \%$ & 2 & Kurang efisien \\
\hline$>100 \%$ & 1 & Tidak efisien \\
\hline
\end{tabular}

c. Efektivitas

Tabel 3

\begin{tabular}{lll}
\hline & Nilai (\%) & Kategori \\
\hline$>100 \%$ & Sangat Efektif & \\
\hline $90 \%-100 \%$ & Efektif \\
\hline $80 \%-90 \%$ & Cukup efektif \\
\hline $60 \%-80 \%$ & Kurang efektif \\
\hline$<60 \%$ & Tidak efektif
\end{tabular}

2. Untuk Perspektif Pelanggan, Perspektif Proses Bisnis Internal dan Perspektif Pertumbuhan dan Pembelajaran, tingkat kepuasan pelanggan diukur dengan menggunakan rumus:

Tingkat Kepuasan $=\frac{\text { Skor persepsi }}{\text { Skor Harapan }} \times 100 \%$

Dengan kriteria pengambilan keputusan menurut Sugiyono (2010) adalah:

Tabel 4

\begin{tabular}{|c|c|c|}
\hline Nilai (\%) & Skala & Kategori \\
\hline $84,01 \%-100 \%$ & 5 & Sangat Puas \\
\hline $68,01 \%-84 \%$ & 4 & Puas \\
\hline $52,01 \%-68 \%$ & 3 & Cukup puas \\
\hline $36,01 \%-52 \%$ & 2 & Kurang puas \\
\hline $20,00-36 \%$ & 1 & Sangat tidak puas \\
\hline
\end{tabular}

Untuk mengetahui kinerja secara keseluruhan maka dilakukan pembobotan untuk masing-masing kinerja berdasarkan perspektif Balanced Scorecad. Metode pembobotan menggunakan teknik pembobotan Dally (2010) yang disesuaikan dengan kebutuhan penulisan.

Setelah melakukan pembobotan dan di dapatkan nilai total skor, maka skor kinerja akhir Dinas Kelautan dan Perikanan Kabupaten Situbondo dengan pendekatan Balanced scorecard dinilai dengan skala likert seperti pada table 5 berikut: 
Tabel 5

\begin{tabular}{lll}
\hline \multicolumn{1}{c}{ Nilai (Skor) } & \multicolumn{1}{c}{ Skala } & \multicolumn{1}{c}{ Kategori } \\
\hline $115-135$ & 5 & Sangat Baik \\
\hline $93-114$ & 4 & Baik \\
\hline $71-92$ & 3 & Cukup Baik \\
\hline $49-70$ & 2 & Tidak Baik \\
\hline $27-48$ & 1 & Sangat Tidak Baik \\
\hline
\end{tabular}

Sumber: Sugiyono, 2010 diolah kembali

\section{HASIL DAN PEMBAHASAN}

\section{Perspektif Keuangan}

Analisis terhadap kinerja keuangan dilakukan dengan menganalisis nilai value for money yaitu dengan menganalisis nilai ekonomis, efisiensi dan efektifitas anggaran sebagai berikut:

a. Ekonomis

Pagu anggaran DKP Situbondo pada tahun 2015 adalah sebesar Rp 16.337.974.086,- dengan realisasi hingga akhir masa anggaran adalah sebesar $\mathrm{Rp}$ 15.561.969.500,- . Terdapat selisih antara pagu anggaran dengan realisasinya yaitu sebesar Rp 776.004.586,-. Tingkat penyerapan anggaran adalah sebesar 95,25\%. Dalam hal ini dapat dikatakan bahwa pelaksanaan kegiatan di DKP Situbondo dikategorikan Ekonomis.

b. Efisiensi

Penghitungan nilai efisiensi anggaran tahun 2015 di DKP Situbondo adalah 222,28\%. penyerapan anggaran di DKP Situbondo dikategorikan Tidak Efisien.

c. Efektivitas

Hasil capaian kinerja pendapatan DKP Situbondo pada tahun 2015 adalah Rp 69.821.000,- dari target pendapatan sebesar Rp 61.000.000,-. Dari hasil capaian kinerja tersebut maka dapat dihitung tingkat efektivitasnya adalah $114,46 \%$, dan termasuk dalam kategori Sangat Efektif.

Hasil wawancara pada perspektif keuangan didapatkan keterangan bahwa diperlukan perhitungan potensi perikanan untuk menaikkan PAD.

\section{Analisa Service Quality (Servqual)}

Tabel 6 Skor Servqual Berdasarkan Peringkat

\begin{tabular}{|c|c|c|c|}
\hline Keterangan & Persepsi & Harapan & GAP \\
\hline Sistem promosi pegawai & 3,1 & 4,38 & $-1,29$ \\
\hline
\end{tabular}




\begin{tabular}{l|l|l|l}
\hline \multicolumn{1}{c}{ Keterangan } & \multicolumn{2}{c}{ Persepsi } & \multicolumn{1}{l}{ Harapan } \\
\hline Kesesuaian jumlah pegawai & 2,76 & 4,05 & $-1,29$ \\
\hline Tangible & 3,16 & 4,41 & $-1,26$ \\
\hline Kesesuaian kualifikasi pegawai & 3,19 & 4,24 & $-1,05$ \\
\hline Kondisi ruang kerja & 3,19 & 4,43 & $-1,24$ \\
\hline Kesesuaian pendidikan pegawai & 2,95 & 4,19 & $-1,24$ \\
\hline Responsiveness & 3,33 & 4,5 & $-1,17$ \\
\hline Reliabiity & 3,37 & 4,5 & $-1,13$ \\
\hline Empathy & 3,44 & 4,52 & $-1,08$ \\
\hline Assurance & 3,47 & 4,53 & $-1,07$ \\
\hline Kondisi ketersediaan sarana prasarana & 3,38 & 4,43 & $-1,05$ \\
\hline Jumlah ketersediaan sarana prasarana & 3,33 & 4,33 & -1 \\
\hline Ketepatan pelaksanaan program dengan perencanaan & 3,43 & 4,38 & $-0,95$ \\
\hline Sistem reward dan punishment & 3,14 & 4,1 & $-0,95$ \\
\hline Pembinaan oleh pimpinan & 3,67 & 4,52 & $-0,86$ \\
\hline Kemampuan pegawai dalam mengatasi hambatan & 3,52 & 4,38 & $-0,86$ \\
\hline Komunikasi diantara pegawai & 3,62 & 4,43 & $-0,81$ \\
\hline Kesesuain pemberian pelayanan (SPM) & 3,52 & 4,33 & $-0,81$ \\
\hline Pemberian kesempatan untuk meningkatkan kompetensi & 3,48 & 4,29 & $-0,81$ \\
\hline Pemberian kesempatan melanjutkan pendidikan & 3,62 & 4,38 & $-0,76$ \\
\hline Kelayakan sarana dan prasarana & 3,52 & 4,24 & $-0,71$ \\
\hline Kondisi lingkungan pekerjaan & 3,76 & 4,38 & $-0,62$ \\
\hline Sistem absensi & 4,24 & 4,52 & $-0,29$ \\
\hline Sistem kerjasama tim & 4,29 & 4,33 & $-0,05$ \\
\hline & & & \\
\hline
\end{tabular}

Berdasarkan tabel servqual didapatkan semua aspek bernilai negatif yang berarti bahwa haapan yang diinginkan pelanggan lebih tinggi dari persepsi yang dia rasakan saat ini. Sehingga dapat disimpulkan kinerja dinas masih belum memuaskan sepenuhnya (POOR). Nilai Gap terbesar terdapat pada aspek sistem promosi pegawai yang ditunjukkan pada nilai -1,29 dan diikuti dengan aspek kesesuaian jumlah pegawai yang juga didapatkan nilai negatif $-1,29$, hal ini menunjukkan aspek promosi pegawai dan kesesuaian jumlah pegawai merupakan dimensi yang paling memberikan efek langsung terhadap kepuasan pelanggan.Pangkat dan jabatan akan berdampak baik terhadap peningkatan kesejahteraan secara finansial maupun aktualisasi diri. Pegawai membutuhkan sistem promosi jabatan yang adil dan transparan Aspek kesesuaian jumlah pegawai juga tidak kalah pentingnya. 
Jumlah pegawai harus seimbang dengan beban kerja dinas. Jumlah pegawai yang terlalu sedikit akan mempengaruhi kinerja karena beban kerja yang berlebih.

Untuk nilai Gap terkecil terdapat pada aspek sistem kerjasama tim, didapatkan nilai $-0,05$ dimana hampir mendekati 0 , yang berarti bahwa perspektif kinerja sudah hampir mendekati harapan. Berdasarkan data service quality, diperlukan analisa untuk menentukan skala prioritas dalam usaha perbaikan dari setiap aspek yang ada. Cara untuk menentukan skala prioritas perbaikan yang ada adalah dengan menggunakan metode Importance Performance Analysis (IPA). Metode IPA akan di tampilkan dalam pembahasan berikutnya.

Analisis Importance Performance Analysis (IPA)

Tabel 7

\begin{tabular}{|c|c|c|}
\hline Kuadran & Faktor Perspektif & Keterangan \\
\hline 1 & $\begin{array}{l}\text { Reliability/ Tampilan Fisik } \\
\text { Responsiveness/ Daya Tanggap } \\
\text { Assurance/ Jaminan } \\
\text { Empathy/ Perhatian } \\
\text { Kondisi Sarana dan Prasarana } \\
\text { Pendidikan Pegawai } \\
\text { Ketepatan Pelaksanaan Program } \\
\text { dengan Perencanaan } \\
\text { Kondisi ruang kerja } \\
\text { Sistem Promosi Pegawai } \\
\text { Komunikasi di antara Pegawai }\end{array}$ & $\begin{array}{l}\text { Merupakan faktor prioritas } \\
\text { utama, faktor ini dianggap } \\
\text { sangat penting oleh pelanggan, } \\
\text { namun untuk saat ini kinerja } \\
\text { dinas kelautan dan perikanan } \\
\text { masih dianggap belum dapat } \\
\text { memuaskan harapan. } \\
\text { Diperlukan fokus dan kerja } \\
\text { keras untuk meningkatkan } \\
\text { kinerja pada kuadran ini. }\end{array}$ \\
\hline 2 & $\begin{array}{l}\text { Kualifikasi Pegawai } \\
\text { Kemampuan Mengatasi Hambatan } \\
\text { Pembinaan oleh Pimpinan } \\
\text { Sistem Absensi }\end{array}$ & $\begin{array}{l}\text { Faktor-faktor pada kuadran ini } \\
\text { sangat penting dan merupakan } \\
\text { faktor penunjang kepuasan } \\
\text { pelanggan. Pelanggan sudah } \\
\text { sangat puas oleh kinerja dinas, } \\
\text { diharapkan dinas kelautan dan } \\
\text { perikanan dapat } \\
\text { mempertahankan prestasi yang } \\
\text { telah dicapai. }\end{array}$ \\
\hline
\end{tabular}




\begin{tabular}{lll}
\hline Kuadran & \multicolumn{1}{c}{ Faktor Perspektif } & \multicolumn{2}{c}{ Keterangan } \\
\hline 3 & Tangible / Dimensi Fisik & Pada kuadran ini faktor -faktor \\
& Jumlah Sarana dan Prasarana & yang ada dianggap tidak \\
& Jumlah Pegawai & penting karena tidak terlalu \\
& Pemberian Kesempatan Meningkatkan & diharapkan oleh pelanggan. \\
& Kompetensi & Sehingga dinas kelautan tidak \\
& Sistem Reward dan Punishment & perlu memprioritaskan atau \\
& & memberi perhatian lebih pada \\
& Kelayakan Sarana dan Prasarana & Faktor -faktor pada kuadran ini \\
& Kesesuaian Pemberian Pelayanan & dianggap tidak terlalu penting \\
& Pemberian Kesempatan Melanjutkan & oleh pelanggan dan tidak \\
Pendidikan & diharapkan, sehingga dinas \\
Kondisi Lingkungan Pekerjaan & dapat \\
Kerjasama Tim & sumberdayanya untuk prioritas \\
& yang lebih utama dahulu. \\
\hline
\end{tabular}

Hasil wawancara dengan informan pada perspektif pelanggan perlu peningkatan kinerja pada aspek tangible untuk perluasan halaman tempat pelelangan ikan, reliability dengan meningkatkan ketrampilan agar dapat memberi solusi yang ekonomis, responsiveness bekerja sama dengan kelompok masyarakat pengawas dalam penanganan konflik dan menjaga ekosistem, emphaty penambahan jumlah petugas dalam melakukan pelayanan masyarakat.

Hasil wawancara perspektif proses bisnis internal didapatkan perlunya diadakan perbaikan maupun update teknologi baru seperti komputer dan internet untuk kelancaran operasional. Perlunya penambahan pegawai dengan kualifikasi keahlian serta pendidikan yang sesuai dengan beban kerja. Penyusunan rencana dan program kerja harus memiliki manfaat terhadap masyarakat.

Hasil wawancara perspektif pertumbuhan dan pembelajaranmenyatakan kebijakan pimpinan untuk memfasilitasi pegawai dalam meningkatkan disiplin serta motivasi kerja sudah dilakukannamun kondisi ruang kerja a kurang nyaman karena sempit dan pengap.

\section{Skala dan Instrumen Pengukuran}

Pada metode skoring berdasarkan kriteria skala dan instrument pengukuran, maka didapat nilai kinerja BSC secara keseluruhan: 
Tabel 8 Format Bobot Keseluruhan Balanced Scorecard

\begin{tabular}{|c|c|c|c|c|}
\hline No. & Perspektif & Dimensi & Aspek Yang diukur & Skor (1-5) \\
\hline \multirow[t]{4}{*}{1.} & Keuangan & Anggaran & 1.Ekonomis & 4 \\
\hline & & & 2.Efisiensi & 1 \\
\hline & & & 3.Efektifitas & 5 \\
\hline & Skor Keseluruh & & & 10 \\
\hline \multirow[t]{6}{*}{2.} & Pelanggan & Kepuasan & 1. Tangibility & 4 \\
\hline & & Pelanggan & 2. Reliability & 4 \\
\hline & & & 3. Responsiveness & 4 \\
\hline & & & 4. Assurance & 4 \\
\hline & & & 5. Emphaty & 4 \\
\hline & Skor & Keseluruhan & & 20 \\
\hline \multirow[t]{12}{*}{3.} & Proses Bisnis & Fasilitas & 1.Kondisi Sarana Prasarana & 4 \\
\hline & Internal & & 2.Jumlah Sarana Prasarana & 4 \\
\hline & & & 3.Kelayakan Sarana Prasarana & 4 \\
\hline & & Sumberdaya & 1. Kesesuaian Jumlah Pegawai & 4 \\
\hline & & Manusia & 2. Kesesuaian Kualifikasi pegawai & 4 \\
\hline & & & 3. Kesesuaian Pendidikan & 4 \\
\hline & & & Pegawai & \\
\hline & & Proses & $\begin{array}{l}\text { 1. Ketepatan pelaksanaan } \\
\text { program dengan perencanaan }\end{array}$ & 4 \\
\hline & & & $\begin{array}{l}\text { 2. Kemampuan pegawai dalam } \\
\text { mengatasi hambatan }\end{array}$ & 4 \\
\hline & & & 3. Kesesuain pemberian & 4 \\
\hline & & & pelayanan & \\
\hline & Skor & Keseluruhan & & 36 \\
\hline \multirow[t]{8}{*}{4.} & $\begin{array}{l}\text { Pertumbuhan } \\
\text { dan }\end{array}$ & Kemampuan & $\begin{array}{l}\text { 1. Pemberian kesempatan untuk } \\
\text { meningkatkan kompetensi }\end{array}$ & 4 \\
\hline & Pembelajaran & & 2. Pemberian kesempatan & 4 \\
\hline & & & melanjutkan pendidikan & \\
\hline & & & 3. Kondisi ruang kerja & 4 \\
\hline & & & 4. Pembinaan oleh pimpinan & 4 \\
\hline & & & 5. Kondisi lingkungan pekerjaan & 5 \\
\hline & & Motivasi & 1. Sistem absensi & 5 \\
\hline & & & 2. Sistem promosi pegawai & 4 \\
\hline
\end{tabular}




\begin{tabular}{llr}
\hline & 3. Sistem reward dan punishment & \multicolumn{1}{l}{4} \\
& 4. Komunikasi diantara pegawai & 4 \\
& 5. Sistem kerjasama tim & \multicolumn{2}{c}{5} \\
\hline Skor & Keseluruhan & 43 \\
\hline TOTAL SKOR & & 109 \\
\hline
\end{tabular}

Didapatkan data total skor 109, merujuk pada Tabel 5 Nilai Kinerja Akhir Balanced Scorecard, disimpulkan kinerja secara keseluruhan pada Dinas Kelautan dan Perikanan dengan menggunakan metode balance scorecard dikategorikan Baik.

\section{Kesimpulan}

Berdasarkan analisa dan pembahasan hasil penelitian maka dapat ditarik beberapa kesimpulan sebagai berikut:

1. Perspektif keuangan menggunakan analisa value for money yang mengukur tingkat ekonomis, efisiensi dan efektifitas. Dari hasil perhitungan di dapatkan data pada aspek ekonomis dengan tingkat penyerapan anggaran 95,25\%, masuk dalam kategori ekonomis. Pada aspek efisiensi sebesar $222,88 \%$ masuk dalam kategori tidak efisien, sedangkan aspek efektifitas memiliki nilai $114,46 \%$ dimana dikategorikan sangat efektif.

2. Perspektif pelanggan memiliki 5 dimensi yaitu tangible, reliability ,responsiveness, assurance dan emphaty, kualitas kinerja ke 5 dimensi tersebut rata-rata memiliki skor 4 yang dikategorikan baik, namun masih perlu peningkatan kinerja berdasarkan analisa servqual yang bernilai negatif yang berarti kualitas pelayanan yang diharapkan masih lebih tinggi bila dibanding yang pelayanan yang dirasakan

3. Perspektif proses bisnis internal memiliki 3 dimensi yaitu dimensi fasilitas, dimensi sumberdaya manusia, dan dimensi proses, masing-masing dimensi memiliki 3 aspek/variabel kinerja. Hasil skoring menunjukkan aspek-aspek dari ke 3 dimensi tersebut rata-rata memiliki skor 4 yang di kategorikan pelayanan sudah baik. Jika dilihat dari metode servqual maka kinerja masih perlu di tingkat dimana semua aspek memiliki nilai negatif yang berarti pelanggan memiliki harapan yang lebih tinggi dari pelayanan yang telah dirasakan.

4. Perspektif pertumbuhan dan pembelajaran memiliki 2 dimensi yaitu dimensi fasilitas dan dimensi proses yang di dalamnya terdapat 10 aspek kinerja, berdasarkan hasil skoring 8 aspek memiliki skor 4 atau PUAS dan 2 aspek kinerja memiliki skor 5 atau Sangat Memuaskan. Jka di rata-rata di dapatkan angka 4 yang berarti kesimpulan kinerja pertumbuhan dan pembelajaran masuk kategori puas. Dari 10 aspek tersebut setelah di analisa menggunakan metode servqual mendapatkan nilai 
negatif, ini berarti kinerja tetap harus terus di tingkatkan untuk memenuhi kepuasan pelanggan.

5. Hasil total skor keseluruhan dari pengukuran Balanced Scorecard di dapatkan nilai 109 yang berarti kinerja Dinas Kelautan dan Perikanan Kabupaten Situbondo dikategorikan BAIK.

\section{Saran}

Berdasarkan kesimpulan yang diperoleh, maka dapat disusun beberapa saran untuk peningkatan kinerja pada Dinas Kelautan dan Perikanan, yaitu:

1. Dinas Kelautan dan Perikanan diharapkan menjadikan hasil penelitian ini menjadi acuan dalam mengukur serta meningkatkan kinerja dinas

2. Pencapaian kinerja keuangan sudah cukup baik dari segi ekonomis dan efektifitas, namun dari segi efisiensi perlu untuk ditingkatkan, dengan cara melakukan penghitungan potensi optimal pendapatan dan retribusi, sehingga dapat menaikkan pendapatan asli daerah dari sektor kelautan perikanan.

3. Pencapaian kinerja pelanggan berada pada kategori baik, namun analisa service quality serta IPA menunjukkan perlu peningkatan kinerja yaitu pada aspek tangible untuk perluasan halaman tempat pelelangan ikan, aspek reliability dengan meningkatkan ketrampilan agar dapat memberi solusi yang ekonomis, aspek responsiveness bekerja sama dengan kelompok masyarakat pengawas dalam penanganan konflik dan menjaga ekosistem, aspek emphaty penambahan jumlah petugas dalam melakukan pelayanan masyarakat.

4. Pencapaian kinerja proses bisnis internal rata-rata sudah baik, namun dilihat dari analisa servqual dan IPA dimana harapan lebih tinggi, maka perlu dilakukan peningkatan kinerja. Pada dimensi fasilitas perlu diadakan perbaikan maupun update teknologi baru seperti komputer, internet, untuk kelancaran operasional. Untuk dimensi Sumberdaya Manusia perlunya penambahan pegawai dengan kualifikasi keahlian serta pendidikan yang sesuai dengan beban kerja. Peningkatan kinerja pada dimensi proses yaitu penyusunan rencana dan program kerja harus memiliki manfaat terhadap masyarakat dengan kualitas pelayanan yang meningkat dari sebelumnya.

5. Pencapaian kinerja pertumbuhan dan pembelajaran rata - rata baik, namun perlu ditingkatkan kinerjanya pada berdasarkan analisa IPA dan servqual yang bernilai negatif. Pada dimensi kemampuan dimana ruangan kerja yang sempit menimbulkan ketidaknyamanan dalam bekerja sehingga membutuhkan ruangan yang mencukupi. Peningkatan kinerja yang perlu dilakukan pada dimensi proses 
yaitu sistem promosi pegawai yang adil serta kerjasama dan komunikasi antar pegawai harus makin solid.

\section{Daftar Referensi}

Firdaus, Dony Waluya. 2011. Membangun dan Implementasi Balanced scorecard Pada Sektor Publik. Majalah IImiah Unikom Vol. 9 No.1

Kaplan, Robert S.. dan David P. Norton, 2000. Balanced Scorecard: Menerapkan Strategi Menjadi Aksi. Jakarta, Penerbit Erlangga

Machmud, Senen. 2013. Aplikasi Konsep Balanced scorecard Sebagai Tolak Ukur Kinerja Pemerintah Daerah. Majalah Bisnis dan Iptek Vol.6, No2., Oktober 2013, 51-66

Miles, M.B \& Huberman, A.M. 1992. Qualitative Data Analysis: A Sourcebook Of New Methods. California: Sage

Mutaqien, Zainal. 2006. Penilaian Kinerja Lima Puskesmas Di Kota Cirebon Dengan Pendekatan Balanced Scorecard. Tesis Program Pasca Sarjana MPKP FEUI

Salamah, Yananda. 2014. Branding Tempat, Membangun Kota, Kabupaten, dan Propinsi Berbasis Identitas. Jakarta : Makna Informasi

Sugiyono, 2010. Statistika Untuk Penelitian. Bandung: Alfabeta 